\title{
A Alteridade Negada: o "Descobrimento" das Américas Segundo o Discurso Imagético de Selos Europeus de 1992* \\ Helmut Renders**
}

\section{Introdução}

Apesar do crescente interesse em selos postais entre historiadores (REID, 1984, p. 223-249) e antropólogos (FREWER, 2002, p. 1-19), os selos são pouco estudados como mensagens imagéticas sociopolíticas, socioeconômicas e sociorreligiosas. Entretanto, "Em seu nível mais básico, bandeiras, selos postais e feriados nacionais servem para confirmar distinções" entre os Estados (ATHREYE et al., 2004, p. 198-199). De fato, selos são também usados para divulgar mensagens políticas (RAENTO; BRUNN, 2005, p. 145-163), para expressar as ideias de um país a respeito do outro (NEWMAN, 1989, p. 70-82; DEANS; DOBSON, 2005) e, como um tipo de embaixador (ALTMAN, 1991), para articular ideologias nacionais e coloniais, inclusive da época do império português (CUSACK,

* Artigo recebido em 12 de dezembro de 2012 e aprovado para publicação em 20 de maio de 2014.

** Coordenador do Programa de Pós-Graduação em Ciência da Religião da Universidade Metodista de São Paulo (UMESP), São Paulo, SP, Brasil. E-mail: helmut.renders@metodista.br. 
2005, p. 591-612) ou do Brasil contemporâneo (SALCEDO, 2006; 2008). Selos podem até provocar conflitos (CHILD, 2008, p. 1) entre países.

Em termos metodológicos, estes documentos podem ser lidos como um discurso da história visual e cultural (MENESES, 2003, p. 11-36); em termos antropológicos, aplicam-se à teoria do poder das representações da picture theory (MITCHELL, 1987; 1994) ou da antropologia histórica (WULF, 2013), que usamos, por exemplo, para a interpretação de fenômenos religiosos como o fundamentalismo religioso (RENDERS, 2008, p. 87-107) ou a religião brasileira colonial e contemporânea (RENDERS, 2009a, p. 373-413; 2009b, p. 116-153).

Neste artigo, propomo-nos a investigar as narrativas imagéticas referentes às relações entre a Europa e as Américas com base em selos postais europeus. Na primeira seção, "A alteridade compreendida", elaboramos um referencial teórico baseado em Todorov (1991) e Dussel (1993) para interpretar as relações entre a Europa e as Américas; na segunda, "A alteridade negada", descrevemos as narrativas imagéticas filatélicas dos selos colocados em circulação em 1992 de forma qualitativa. Na terceira seção, apresentamos um resumo comparativo e quantitativo para destacar as grandes tendências, os discursos dominantes e as exceções, na base dos eixos interpretativos e conceitos-chave fornecidos por Todorov e Dussel.

\section{A Alteridade Compreendida: Referencial Teórico para a Análise do Discurso Imagético}

Escolhemos como referencial teórico dois analistas da relação entre a Europa e as Américas e especialistas na época colonial. Um é europeu, outro, latino-americano, e ambos, Tzvetan Todorov (1991) e 
A Alteridade Negada: 0 "Descobrimento" das Américas Segundo o Discurso Imagético...

Enrique Dussel (1993), analisam a conquista da América Latina em uma época próxima à data da apresentação dos selos (1992).

\subsection{Tzvetan Todorov}

Todorov (1991, p. 183ss), em sua "Tipologia das relações com outrem", distingue três tipos principais de relacionamentos entre culturas:

- Julgamentos de valor (ser bom ou mau, gostar de ou não gostar de);

- Ações de aproximação ou distanciamento (adoção de valores, assimilação do outro e submissão ao ou do outro);

- Conhecimento do outro ou continuação da ignorância.

Todorov (1991, p. 184) afirma: "Conquistar, amar e conhecer são comportamentos autônomos e, de certo modo, elementares. [...] descobrir [...] está mais relacionado à terra do que aos homens; [...] a atitude de Colombo pode ser descrita em termos inteiramente negativos: não gosta, não conhece e não se identifica."

Quanto ao primeiro eixo, Todorov (1991, p. 188ss) traz como exemplo Las Casas, sua compreensão do cristianismo como religião universal e sua tendência de julgar diferentes culturas segundo seu suposto nível de desenvolvimento, o que leva Las Casas a não aceitar a coexistência de ideias e valores.

É em nome da moral cristã que os católicos [...] veem os índios como iguais a eles, portanto, semelhantes a eles, e tentam assimilá-los a si mesmos. Com as mesmas referências em mente, os protestantes, ao contrário, apontam as diferenças e isolam suas comunidades das indígenas quando se encontram em situação de contato. Em ambos os casos, nega-se a identidade do outro: quer seja no plano da existência, como no caso dos católicos; ou no plano dos valores, como os protestantes; é um tanto derri- 

dista na via da destruição do outro (TODOROV, 1991, p. 189ss).

Quanto ao segundo eixo, Todorov (1991, p. 193) discute Vasco de Quiroga. Ele o interpreta como um humanista que considera a cultura hispânica decadente e que encontra nos indígenas atitudes dos primeiros apóstolos, sem achá-los perfeitos. Em consequência, Quiroga concentra seus esforços na ação transformadora entre os próprios índios na busca da criação da sociedade ideal.

Quanto ao terceiro eixo, Todorov menciona Diego Durán (TODOROV, 1991, p. 199ss) e Bernardino de Sahagún (TODOROV, 1991, p. $217 \mathrm{ss}$ ). O primeiro defenderia a necessidade de um conhecimento das religiões indígenas para evangelizá-los e identifica o sincretismo como estratégia indígena de sobrevivência cultural (TODOROV, 1991, p. 202ss). Além disso, afirma que as próprias religiões indígenas teriam elementos cristãos. "As antigas crenças ainda são tantas, tão complexas, tão semelhantes às nossas em vários casos, que se encavalam" (TODOROV, 1991, p. 204). Para explicar esta semelhança, Durán constata uma missão católica anterior ou relações com uma tribo perdida de Israel (TODOROV, 1991, p. 206). Consequentemente, Duran até admira textos indígenas (TODOROV, 1991, p. 208-209) e os traduz. Sahagún, por sua vez, gramático ou linguista de profissão, aprende nahuatal e ensina latim às crianças da nobreza asteca. Torna-se defensor da cultura nahuatal e escreve sua história da cultura local e da conquista primeiro em nahuatal, depois em espanhol. Ele não julga nem interpreta, mas descreve (TODOROV, 1991, p. 227) a cultura local por meio da técnica literária de distanciamento.

\subsection{Enrique Dussel}

Enrique Dussel nos oferece, em suas conferências com o título $O$ encobrimento do outro: a origem do mito da modernidade, uma múltipla perspectiva sobre a visão europeia das Américas: 
A Alteridade Negada: 0 "Descobrimento" das Américas Segundo o Discurso Imagético...

[...] em 1982, Felipe González expressou que dentro de dez anos [em 1992] se festejaria de maneira muito especial o evento do "descobrimento". A Espanha, que nesses anos procurava entrar no Mercado Comum Europeu, propunha 1492 como uma das suas glórias, à qual poderia se referir perante as outras nações europeias. É evidente que esta "glória" é muito mais manejada hoje pela Espanha do que há dez anos, e justamente em função de sua política de integração à Europa e não tanto como tentativa de compreensão ou apoio à América Latina (DUSSEL, 1993, p. 66).

Na perspectiva de Dussel, os europeus "encobertam" as nações indígenas, e as nações indígenas descobriram os representantes das nações europeias.

Espanha e Portugal [...] são mais nações renascentes [...] são [...] a primeira região da Europa a ter a "experiência" originária de constituir o Outro como dominado e sob controle do conquistador, do domínio do centro sobre a periferia. A Europa se constitui como o "centro" do mundo (DUSSEL, 1993, p. 15, ênfase nossa).

Depois da fase da "invenção" do "ser-asiático" do Novo Mundo, Américo Vespúcio "descobre" que de fato se tratava de um quarto continente, de uma terra que até então não era contada no mundo europeu.

A América não é descoberta como algo que resiste distinta, como o outro, mas como a matéria onde é projetado o "si-mesmo". Então não é o "aparecimento do Outro", mas a "projeção do si-mesmo": encobrimento. [...] a terra tinha sido "des-coberta" como o lugar da "história mundial"; pela primeira vez aparece uma "quarta parte" (América) que se separa da "quarta península" asiática, onde uma Europa se au- 
tointerpreta, também, pela primeira vez, como "centro do acontecer humano em geral", e por isso desenvolve seu horizonte "particular" como horizonte "universal” (DUSSEL, 1993, p. 34-35, ênfase nossa).

Dessa forma, a conquista não é entendida como "uma relação [...] estética ou quase científica da pessoa na natureza, como 'descobrimento' de novos mundos, [...] não de inspeção [...] de novos territórios, mas da dominação" (DUSSEL, 1993, p. 42). Por esta razão, não se deve falar do "encontro dos mundos" porque as estruturas essenciais do outro foram destruídas. Depois dessa distinção, a "colonização [...] do mundo da vida" segue a "práxis guerreira, de violência pura [...] uma práxis erótica, pedagógica, cultural, política, econômica [...] do domínio dos corpos [...] da cultura [...] das instituições" (DUSSEL, 1993, p. 50). A colonização é a estruturação da nova forma de vida imposta. Do mesmo modo funciona a "conquista espiritual". Nem mesmo um Las Casas enxerga no índio mais do que "crianças imaturas" e "bárbaras", se não forem menos ainda, porque "não chegaram ao uso da escrita" (DUSSEL, 1993, p. 63). Em 1492, cria-se realmente a América Latina. "Quer dizer, os indígenas com suas esplêndidas culturas não têm nenhum significado histórico" (DUSSEL, 1993, p. 66).

Diante desse fato de encobrimento, a introdução do conceito "encontro" representa a tentativa de criar um novo mito sobre 1492. Em vez disso, Dussel sugere partir da perspectiva dos habitantes de Abya-Yala, assim um dos nomes indígenas do Novo Mundo dos europeus. Lê-se agora a história como invasão, em vez de conquista, como "des-cobrimento" dos invasores em vez de encobrimento dos invadidos. Partindo da ideia da parúsia de seus deuses, as nações indígenas demoraram a enxergar o caráter de invasão da chegada dos europeus. Depois da percepção mais realista da situação, houve inúmeros levantamentos e uma resistência muito mais ampla do que a normalmente relatada. Esse silêncio sobre a resistência é mais uma forma de 
A Alteridade Negada: 0 "Descobrimento" das Américas Segundo o Discurso Imagético...

não conceder ao outro sua personalidade, sua dignidade, admitir seu saber bélico, sua capacidade de organizar e efetuar uma resistência.

Assim, Dussel questiona também Todorov a respeito de sua perspectiva ainda eurocentrista: "Na obra de Tzvetan Todorov [...] o 'nós' são os europeus, e os 'outros' somos nós, os povos do mundo periférico. A Modernidade se definiu como 'emancipação' em relação a 'nós', mas não percebeu seu caráter mítico - sacrifical em relação aos 'outros"” (DUSSEL, 1993, p. 188).

Diferentemente, Dussel propõe uma superação dessa perspectiva e sugere um projeto designado por ele como "transmodernidade". Aqui se junta - no caso de um desenvolvimento ideal - todo mundo em um projeto de vida, através da práxis de libertação ou da realização do projeto mundial da libertação e da práxis da solidariedade do centro com a periferia por meio de uma constante diminuição dos tipos históricos de dominação (DUSSEL, 1993, p. 188).

\section{A Alteridade Negada: 0 Discurso Imagético dos Selos Euro CEPT de 1992}

Em seguida, interpretaremos discursos imagéticos de selos postais europeus, criados para lembrar o ano de 1492. Nossas perguntas específicas são: como esses selos descrevem o encontro entre europeus e ameríndios? O que ou quem eles escolhem e destacam como central dessa memória nesses selos? Os selos reconhecem os feitos dos povos ameríndios "pré-colombianos" ou glorificam e justificam a conquista e seus agentes europeus? Como eles apresentam a relação do país de origem do selo e as Américas? As suas narrativas imagéticas se alinham a uma das distinções propostas pelos autores? E, olhando o todo, há tendências gerais? 
Os selos foram publicados por países organizados na Conférence Européenne des Administrations des Postes et des Télécommunications (CEPT) e pertencem a uma série anualmente lançada com o nome selos Euro CEPT. ${ }^{1}$ Cada ano se escolhe um tema para representar aspectos e feitos comuns a esses países. Apesar da definição temática, há uma total liberdade de criar a arte dos selos. No caso do tema "1492", houve, porém, duas possibilidades: editar selos Euro CEPT com plena liberdade artística ou lançar um ou mais blocos filatélicos reservados estritamente à memória de Cristóvão Colombo. Para delimitar o número dos objetos a serem investigados, excluímos os blocos filatélicos ou os selos que se referem somente a Colombo enquanto eles não são acompanhados por blocos filatélicos por entendermos que estes países, desde o início, não iam articular outro discurso senão o do herói, ${ }^{2}$ pioneiro e visionário europeu. Em outras palavras, repetir o discurso antigo inalterado. ${ }^{3}$ Outrossim, oferecemos uma redução ainda maior concentrando-nos somente nos países com presença colonial nas Américas e acrescentamos dois discursos alternativos que consideramos exemplares.

\subsection{Memória filatélica dos colonizadores de Abya-Yala}

Observamos, primeiramente, a visão dos países que mantiveram colônias nas posteriormente chamadas Américas: Espanha, Portugal, Inglaterra, França e Holanda. Também acrescemos a Alemanha, mesmo que sua presença se reduza a poucos anos no século XVI. ${ }^{4}$

\section{Espanha}

A Espanha era o país europeu com o maior número de selos e blocos filatélicos lançados em 1992 para comemorar os 500 anos da "descoberta da América". Primeiro, lançou uma reedição de dezesseis selos das comemorações de 1882 em quatro blocos, com Portugal. ${ }^{5}$ 
A Alteridade Negada: 0 "Descobrimento" das Américas Segundo o Discurso Imagético...

Segundo, apresentou um bloco filatélico com três selos em formato triangular, mostrando três vezes a mesma gravura das três embarcações, vistas de frente, supostamente atravessando o Atlântico, nas cores vermelha, azul e cinza. No meio dos três selos, encontra-se uma gravura do monumento de Colombo da cidade de Barcelona. Apresentou mais dois selos (Figuras 1 e 2).

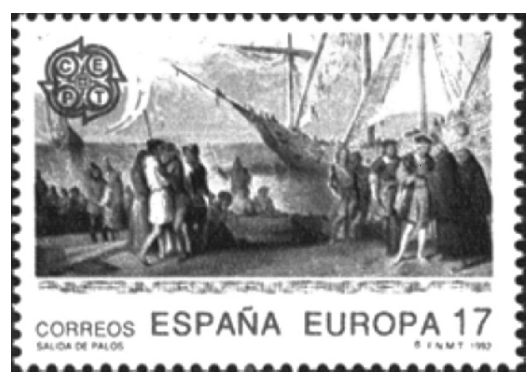

Figura 1

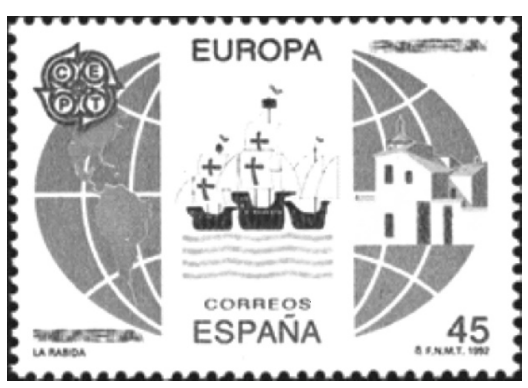

Figura 2

Nesses dois selos, dois lugares são mencionados: Palos de la Frontera (Figura 1), o porto espanhol de partida, e Santa Maria de La Rábida (Figura 2), um monastério cujos freis franciscanos apoiaram Colombo de forma decisiva. Ambas as localidades lembram momentos determinantes dessa viagem. O primeiro selo foca no momento da despedida antes da viagem (Figura 1). À esquerda, marinheiros abraçam, antes da partida, amigos ou familiares. Atrás do grupo, vemos uma bandeira branca com o sinal da cruz em vermelho. À direita, Colombo recebe a bênção de dois freis franciscanos. No fundo, há dois barcos: um já indo em direção do mar; o outro, pronto para partir. Trata-se de uma reprodução parcial de uma pintura. Nela há também o terceiro barco da frota, e Colombo e os freis franciscanos formam o centro. Pelo recorte, fica no centro do selo um vazio. O segundo selo lembra outro momento-chave de 1492: no final do ano de 1491, Colombo tinha desistido de esperar apoio da Espanha e pretendeu ir para a França. No caminho, encontra no monastério de La Rábida o confessor da rainha Isabela, o monge Juan Perez, que ele conhecia 
desde 1485. Os freis franciscanos Perez e Antonio de Marchena tinham estabelecido contato com a Coroa Espanhola e, na ocasião, escreveram mais uma carta à rainha. Eles foram ouvidos, e Colombo se dirigiu a Granada, onde o projeto finalmente foi aprovado. Em seguida, La Rábida tornou-se um centro espiritual importante para os conquistadores da chamada Nova Espanha, entre eles Hernán Cortés e Francisco Pizarro, que passaram por lá em 1528 depois das suas conquistas. Ademais, o monastério enviou os freis Juan de Palos e Juan Izquierdo para a evangelização da nova Espanha, onde Izquierdo, entre 1587 e 1602, seria o bispo de Yucatán.

A viagem parte, pois, tanto de um porto como de um monastério, e as três naus usadas na viagem trazem, em suas velas, o sinal vermelho da cruz para uma terra nova apresentada como vazia (Figura 2). Considerando que a pintura na qual o primeiro selo se baseia também se encontra no monastério de La Rábida, concluímos que os selos espanhóis constroem muitas referências quanto ao aspecto religioso da viagem de Colombo.

\section{Andorra Espanhola}

Os selos da Andorra Espanhola seguem um modelo gráfico parecido com os selos espanhóis e formam com eles uma unidade. Desta vez, o texto refere-se à "Proa da Santa Maria" (Figura 3) e à "Carta de descoberta de Basileia de 1494" (Figura 4).

Em termos náuticos, a "proa" representa simplesmente a frente da nau; em termos metafóricos, pode articular arrogância, orgulho, soberba e vaidade. O fundo do primeiro selo (Figura 3) mostra o sol baixo. Portanto, refere-se à ida, uma vez que a Santa Maria naufragou depois da chegada à América Central. Por conseguinte, a referência ao sol baixo representa o nascer do sol que as embarcações sempre deixam para trás quando partem. 

Américas Segundo o Discurso Imagético...

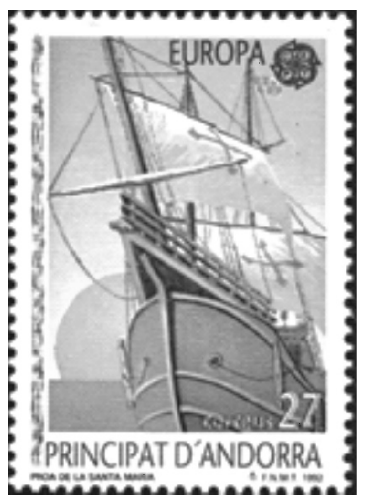

Figura 3

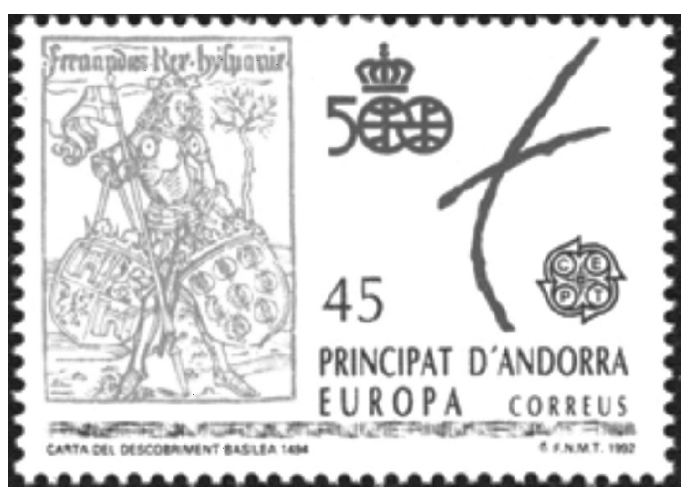

Figura 4

O segundo selo, de acordo com a subscrição, refere-se à "Carta de descobrimento, Basileia, 1494" (Figura 4). Trata-se da carta de Colombo de 1493, que anuncia a descoberta em sua versão em latim. A carta foi rapidamente traduzida para toda a Europa, e o selo mostra dois terços da capa da edição de Basileia de 1494 com o título: "Em louvor ao mais sereno Ferdinand, Rei de Espanha, 'Baetic' e Governante de Granada, Besieger, Victor, Triunfante: e sobre as recém-descobertas ilhas do mar indiano." Era uma versão graficamente sofisticada, escrita em latim e ilustrada com gravuras. O texto é, de fato, composto por duas obras: a primeira fala da reconquista da Espanha em 1493, a segunda é a tradução da carta de Colombo. Quando o selo mostra a gravura do rei Fernando II de Aragão e de Castela, reproduz a gravura inicial da primeira obra que se refere à reconquista da Espanha e não à conquista das Américas. ${ }^{6}$ A carta de descobrimento publicada na Basileia em 1494 transformou o empreendimento de Colombo em assunto político europeu, regulamentado internacionalmente, ainda em 1494, pelo Tratado de Tordesilhas. Nos selos da Andorra Espanhola, transparecem sentidos duplos (a proa e seu significado náutico e linguístico) e ambiguidades (a reconquista se funde com a conquista).

Estudando os quatro selos, identificamos um único elemento transversal: a cruz na cor vermelha sobre o fundo branco. Ela se encontra 
duas vezes nas velas dos navios (Figuras 2 e 3), uma vez como bandeira nas mãos do rei Fernando de Espanha (Figura 4) e uma vez como bandeira levada ao navio (Figura 1). Trata-se de um símbolo antigo que surge com a conquista de Jerusalém como símbolo dos cavaleiros templários.

Os quatro selos lembram os momentos dramáticos da vida de Colombo e das dimensões religiosas e políticas de suas viagens em perspectiva ibérica.

\section{Portugal, Açores e llha da Madeira}

Já mencionamos que Portugal, junto com a Espanha, tinha lançado uma reedição de dezesseis selos das comemorações de 1882. Publicou igualmente um único selo que, com dois selos dos Açores e da Ilha da Madeira, compõem uma unidade formal. Estes três selos destacam momentos importantes que relacionam Colombo a Portugal.

O selo português (Figura 5) lembra a busca de Colombo por apoio financeiro junto ao rei português D. João II. O monarca recebeu Colombo pela primeira vez em 1484 e, pela segunda e última vez, em 1489. Nesses encontros, Colombo informou ao rei seus planos de ir para o oeste para chegar às Índias. Segundo o selo, a conversa ocor-

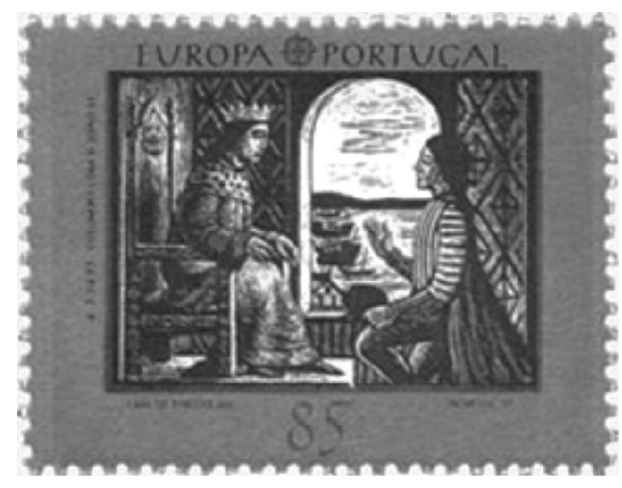

Figura 5 
A Alteridade Negada: 0 "Descobrimento" das Américas Segundo o Discurso Imagético...

reu em um dos palácios do rei, eventualmente, em Sintra. O pedido, porém, foi negado pelo rei, e Colombo muda-se para a Espanha. Como Bartolomeu Diaz já tinha descoberto e comprovado, em 1488, a existência de um caminho marítimo ao redor da África, a Coroa portuguesa não viu a necessidade de fazer mais um investimento.

O selo dos Açores (Figura 6) refere-se à primeira viagem de Colombo em 1492. No selo consta "Colombo em Santa Maria", uma ilha que faz parte do arquipélago dos Açores. Colombo reabasteceu neste lugar água e alimentos antes de enfrentar o Atlântico. Pelos olhares das figuras desenhadas, fixadas na ilha, o selo parece retratar o momento da chegada, com os barcos pequenos aproximando-se da ilha ou barcos da flotilha indo para a ilha. ${ }^{7}$

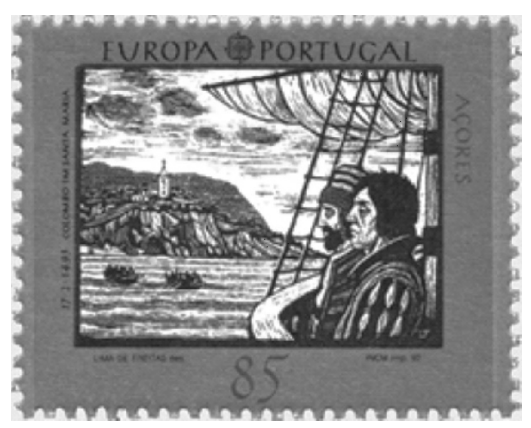

Figura 6

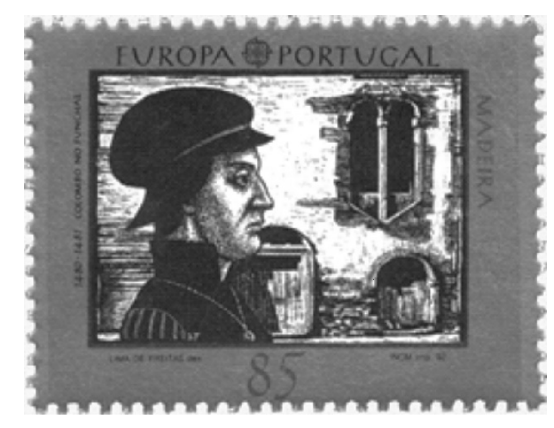

Figura 7

No selo da Ilha da Madeira, lê-se "Colombo em Funchal" (Figura 7). Esta cidade fica perto de Porto Santo. A relação de Colombo com a Ilha da Madeira decorreu de seu casamento com a filha de Bartolomeu Perestrelo, um dos povoadores e primeiro capitão do donatário da ilha. Casado desde 1479 com Felipa Moniz Perestrello, Colombo morou entre 1580 e 1584 em Porto Santo, onde nasceu, em 1580, seu primeiro filho, Diego.

Os selos de Portugal e os de seus territórios localizados no Oceano Atlântico lembram a relação entre Colombo e o país. Não há nenhuma menção da dimensão religiosa ou da descoberta. ${ }^{8}$ 


\section{Inglaterra}

Nos selos ingleses, encontramos o desenho da embarcação Pinta e de um bergantim inglês. Fala-se do Landfall in the Americas $1492 \mathrm{e}$ Christopher Columbus (Figura 8) e da Grand Regatta Columbus 1992 e Operation Raleigh (Figura 9). Landfall não significa nem descobrimento, nem encontro. Landfall, literalmente "aterragem", significa "desembarque". Os navios representam tipos nacionais. No segundo selo, encontra-se um bergantim, um tipo de navio rápido e fácil de manobrar e empregado nos séculos XVII e XVIII para fins de pirataria, espionagem e reconhecimento.

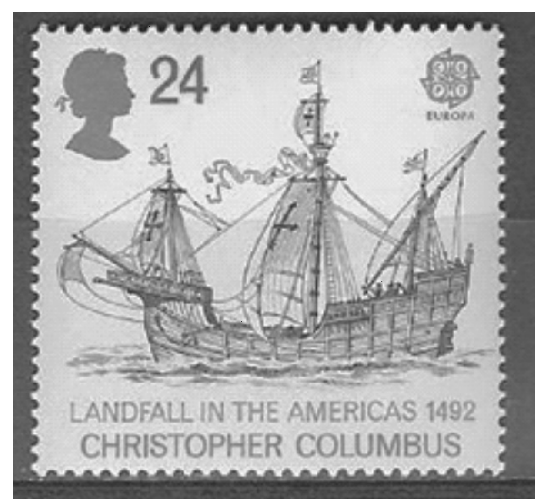

Figura 8

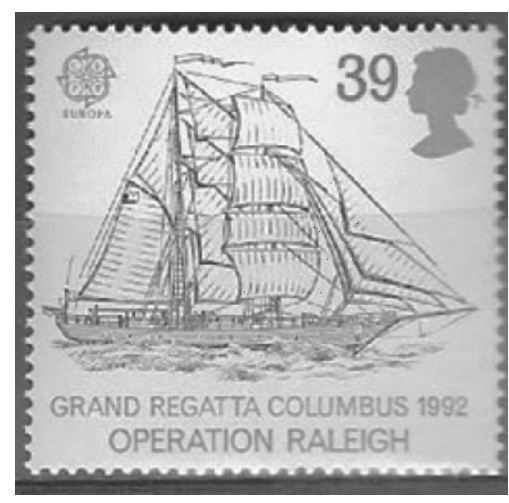

Figura 9

Enquanto o nome Christopher Columbus do primeiro selo é compreensível, a expressão Operation Raleigh requer uma explicação. Trata-se de uma fundação do príncipe Charles que, desde 1983, promove ações ecológicas. Na regata de 1992, esta fundação financiou a participação do bergantim Kaisei, que significa Planeta Oceano e representa uma iniciativa privada e governamental do mesmo nome a favor da limpeza dos oceanos, especialmente do plástico acumulado no Pacífico. Por outro lado, o nome Raleigh lembra também Sir Walter Raleigh (1552-1618), pirata da sua majestade rainha Elizabeth I da Inglaterra e incansável perseguidor de galeões espanhóis. Essas 
A Alteridade Negada: 0 "Descobrimento" das Américas Segundo o Discurso Imagético...

asociações causam uma tensão interpretativa: o segundo selo quer virar a página do passado e prefere falar de novas ameaças da humanidade ou quer referir-se à tradição inglesa como uma tradição marítima que participou das riquezas extraídas da América ibérica? Uma coisa fica evidente: as próprias Américas não são assunto.

\section{A llha de Man}

O Isle of Man usa a data comemorativa de 1992 para se referir ao momento inicial da conquista anglo-saxã das Américas pelos pais peregrinos (cf. Pilgrim fathers, 1620, Figura 10). Os selos mostram dois navios, o Speedwell, no porto de Delfshaven, Holanda (Figura 11), e o Mayflower, em Dartmouth, Inglaterra (Figura 12). Grupos puritanos tinham fugido no início do século XVI para a Holanda. O Speedwell levou reformados holandeses para a Inglaterra para se juntar ao Mayflower.

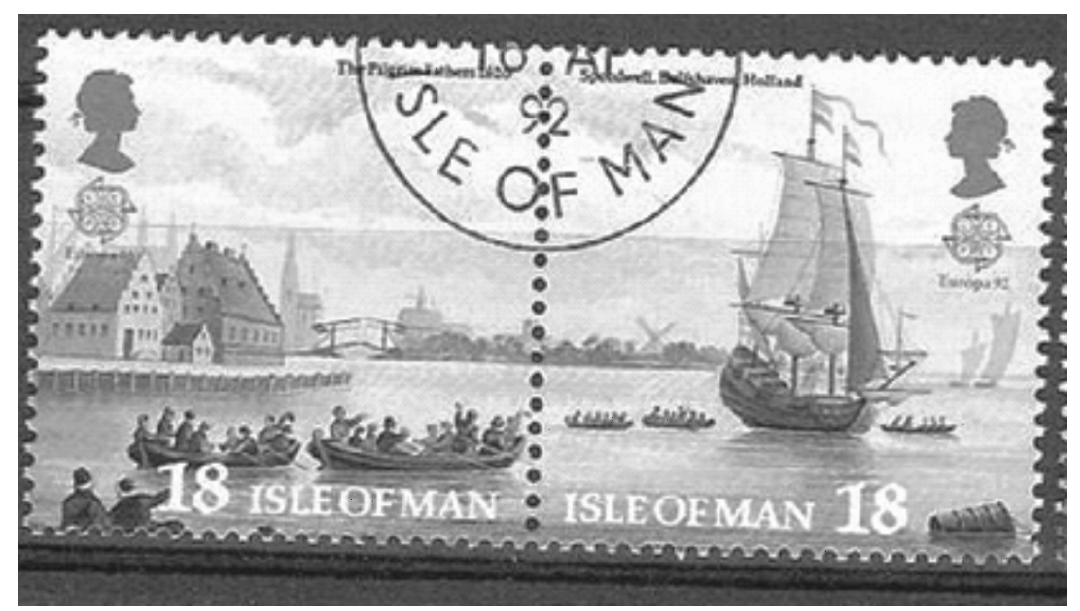

Figura 10

Figura 11

Não está claro se as pessoas nos barcos encontrados nos quatro selos se despedem ou acolhem os navios. 


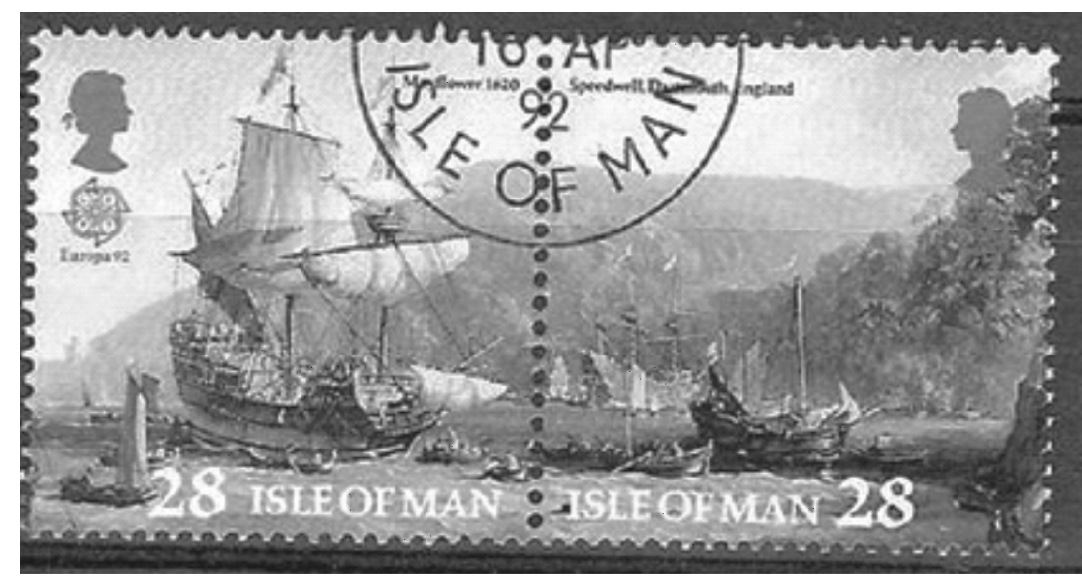

Figura 12

Figura 13

Diferentemente das embarcações de Colombo, não encontramos referências religiosas. Também nesses selos, Abya-Yala, a terra dos ameríndios, não aparece. Foca-se nas origens exatas de alguns homens e de algumas mulheres. Os selos também não articulam outro vínculo entre esses dois barcos e a ilha. O oficial inglês, capitão Myles Standish (1584-1656), contratado como conselheiro de segurança da viagem, tinha - por casamento - um vínculo com a ilha. A Ilha de Man contribuiu com um homem importante para a presença protestante na América do Norte. Ele agiu na colônia com determinação, mas é também lembrado como responsável pelo massacre de indígenas em Wessagusset. A conexão direta da ilha com o "Landfall" desses dois barcos permanece omitida.

\section{Ilha de Jersey}

Nas três imagens da Ilha de Jersey, aparece Colombo como pano de fundo, junto a um globo e uma embarcação. Destacamos, entretanto, três personalidades da conquista.

John Bertram (1796-1882, Figura 14), nascido na ilha, fez fortunas com a navegação entre Inglaterra e as Américas, e se tornou filantro- 
A Alteridade Negada: 0 "Descobrimento" das Américas Segundo o Discurso Imagético...

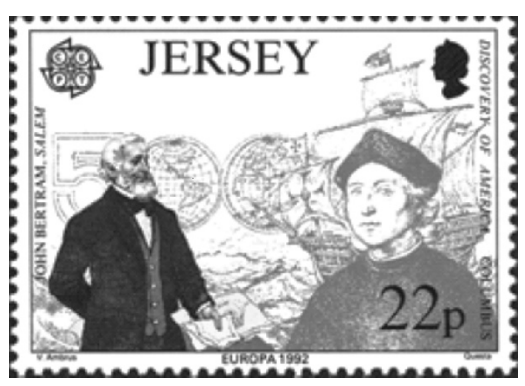

Figura 14

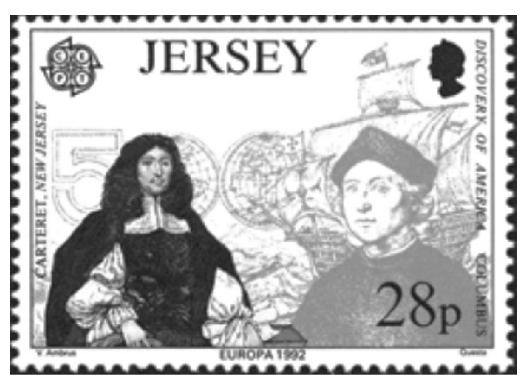

Figura 15

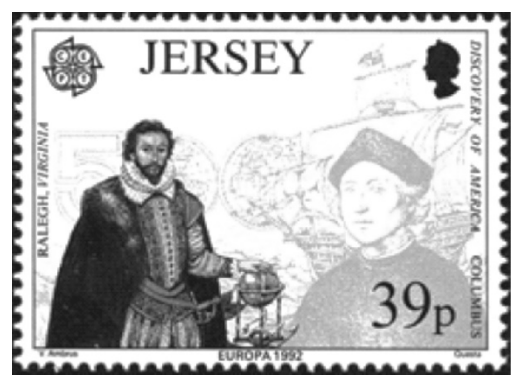

Figura 16

po em Salem, EUA. Sir George Carteret (1610-1680, Figura 15) era oficial e depois capitão naval e foi conhecido pela sua bravura em lutas contra piratas [muçulmanos?] norte-africanos, dos quais libertou presos ingleses, franceses, holandeses e espanhóis. Desempenhou um papel importante na restauração da monarquia inglesa: durante o reinado de Carlos II, foi tesoureiro de toda a armada naval inglesa e se aposentou como um Admiral Sir. No fim da vida, recebeu da Coroa o título de barão e terras nas novas colônias, terras que lembram sua origem (Nova Jersey) e onde fica uma cidade com seu sobrenome de família. O filho, Philippe, tornou-se o primeiro governador do Estado. O terceiro selo apresenta Sir Walter Raleigh (1552-1618, Figura 16), que se encosta a um globo. Raleigh era pirata e explorador inglês em pessoa, um herói nacional. Ele projetou a primeira colonização inglesa - que falhou - no território posteriormente chamado de Virgínia. Todas essas três pessoas são familiarizadas com o mar e se relacionam com uma parte da nova terra: Salem, Nova Jersey e Virgí- 
nia. Homens de ação, empreendedores, heróis - até um filantropo representam os conquistadores ingleses. Novamente, não há qualquer memória das populações originárias encontradas ou de sua importância, sobretudo relativamente às primeiras décadas de sobrevivência dos recém-chegados. A ilha de Nova Jersey apresenta sua participação na construção da conquista inglesa.

\section{Holanda}

Os holandeses deram igualmente destaque a Colombo (Figuras $17 \mathrm{e}$ 18) e garantem isso pela escrita latina de seu nome - "Christopher Columbus" (Figura 17) ou pelo retrato (Figura 18). Nos dois selos, domina o símbolo do círculo. O segundo selo deixa claro que isso não quer ressaltar o conquistador, mas o visionário. Colombo é apresentado como um homem aberto a uma nova ideia: a terra é redonda, não plana. Contudo, não se trata somente de admiração pela sua genialidade náutica (Figura 18).

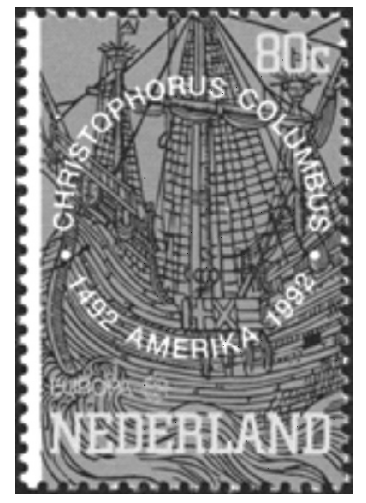

Figura 17

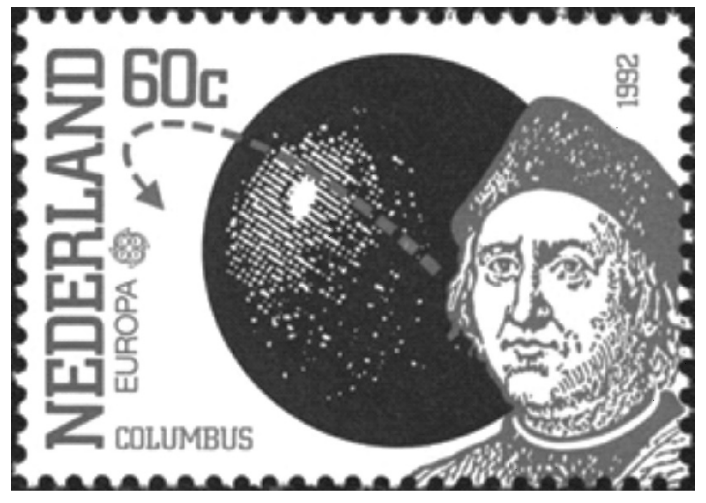

Figura 18

É lembrado o objetivo dessa viagem para o Oeste e não para o Leste: a procura do caminho para as Índias. Colombo é apresentado como um homem que queria encontrar um jeito de "contornar" as rotas do negócio bloqueadas por outras nações, inclusive pelos navios holan- 


\section{A Alteridade Negada: 0 "Descobrimento" das}

Américas Segundo o Discurso Imagético...

deses. Segundo os selos holandeses, a visão mercantil de Colombo é essencial. Pouco importa se ele não chegou à Índia. Tampouco importa quem ou o que ele encontrou no meio do caminho. Nos dois selos não aparecem as Américas nem seus habitantes. De fato, seria a Holanda a grande concorrente especialmente dos portugueses: marginalmente no Brasil e, de forma especial, na Índia.

\section{França}

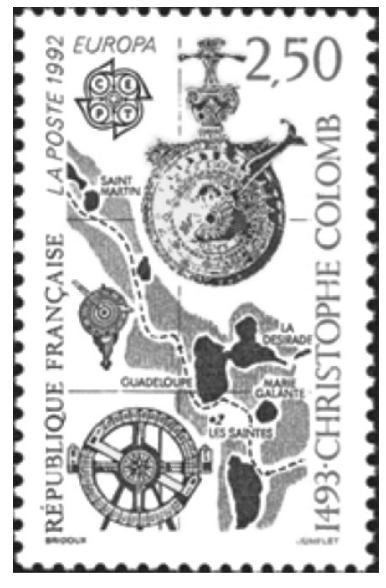

Figura 19

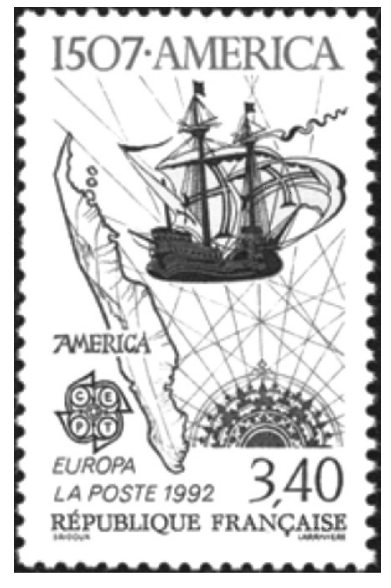

Figura 20

La Grande Nation aproxima-se do tema com cálculos próprios. Mesmo publicando seus selos como toda a Europa em 1992, introduzem-se duas datas diferentes: "1493: Christophe Colomb" (Figura 19) e "1507 America" (Figura 20). No primeiro selo, aparece ainda o nome de Colombo, mas não o seu retrato. Em vez disso, destacam-se instrumentos e mapa náuticos. O mapa do primeiro selo (Figura 19) mostra ilhas com nomes franceses. A França destaca sua posse na América Central e aspectos tecnológicos, no caso, instrumentos náuticos e a arte da cartografia. A outra data, 1507, também chama a atenção (Figura 20). É o início da época pós-colombiana, porque Colombo viveu entre 1451 e 1506. Cálculos próprios, representações de 
instrumentos náuticos, mapas, mas nenhum ser humano. As Américas reduzidas a uma visão instrumental e geopolítica, em uma perspectiva específica francesa.

\section{Andorra Francesa}

Os selos de Andorra Francesa (Figuras 21 e 22) introduzem um tema até agora plenamente ausente: o tema do encontro entre as culturas.

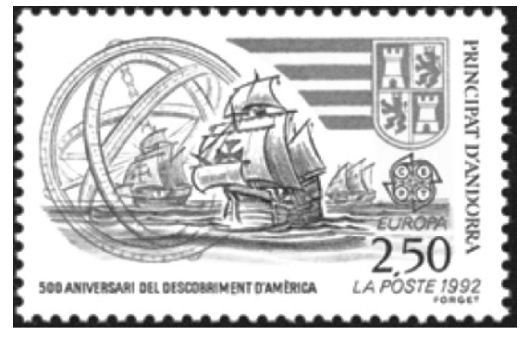

Figura 21

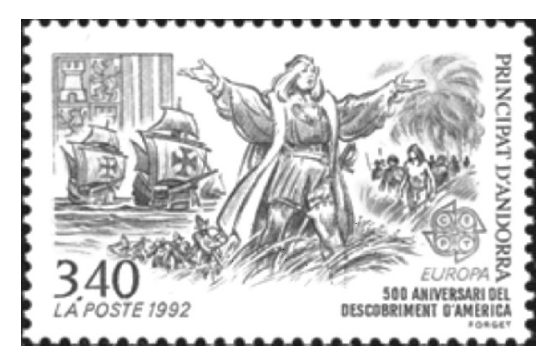

Figura 22

O primeiro selo (Figura 21) articula a travessia guiada pela tecnologia náutica representada em tamanho maior do que as próprias embarcações. O segundo selo (Figura 22) mostra um momento real do descobrimento: a chegada à terra firme. No centro, encontra-se o próprio Colombo; à sua esquerda, embaixo, um grupo de espanhóis; à direita, um grupo de indígenas. Ambos os grupos estão armados. Colombo é retratado com braços abertos. Uma vez que ele não olha na direção dos indígenas, o gesto não necessariamente expressa um acolhimento da parte desse grupo. Os indígenas representam a maioria (oito indígenas contra sete soldados espanhóis, incluindo Colombo). Estando os dois grupos armados, podemos imaginar um futuro conflito.

\section{Alemanha}

Os selos alemães referenciam também gravuras de relatos antigos, escolhem aquelas representações do passado que documentam o en- 


\section{A Alteridade Negada: 0 "Descobrimento" das}

Américas Segundo o Discurso Imagético...

contro entre culturas e pessoas. O primeiro selo (Figura 23a) retrata a chegada da frota de Colombo às Américas de acordo com uma gravura encontrada na carta de Colombo, edição da Basileia de 1493. O segundo selo (Figura 24a) descreve o encontro entre René Goulaine de Laudonnière e o cacique Athore em 1564. O quadro original (Figura 24b) foi pintado por Jacques Le Moyne de Morgues, c. 1570, e pertence hoje à Biblioteca Pública de Nova York. As imagens de ambos os selos apresentam recortes das gravuras ou pinturas originais (Figuras 23b e 24b).

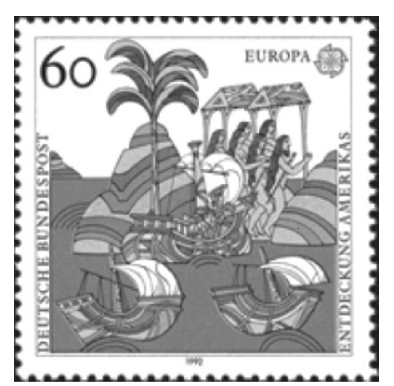

Figura 23a

A frota de Colombo chega às Americas/

Carta de Colombo, edição da Basileia, 1493.

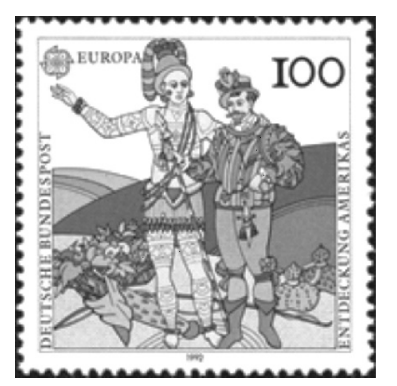

Figura 24a

René Goulaine de Laudonnière e o cacique Athore, 1564.

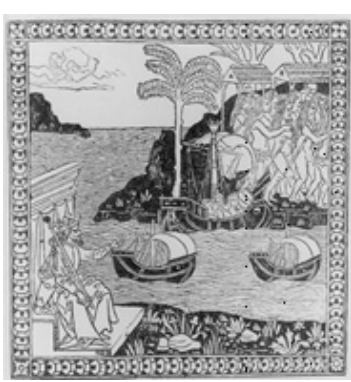

Figura 23b

A frota de Colombo chega às Americas/

Carta de Colombo, edição da Basileia, 1493.

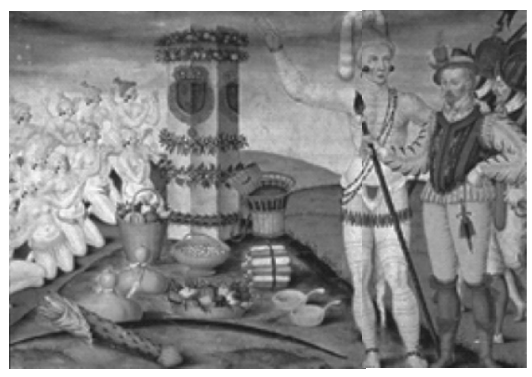

Figura 24b

René Goulaine de Laudonnière e o cacique Athore, visitam a coluna de Ribault, 1564.

Nos selos, eliminam-se assim, por um lado, as referências às monarquias espanhola (o rei sentado, Figura 23b) e francesa (monumento de Ribault, Figura 24b), inclusive aos "súditos" ajoelhados em frente 
da coluna. Por outro lado, os selos lembram que existe uma conquista protestante ao lado da conquista católica. ${ }^{9}$

Nos dois selos, aparecem pessoas do novo e do antigo mundo. No primeiro selo, os marinheiros no barco ao fundo olham para a nova terra, onde há um grupo de mulheres segurando zarabatanas, talvez com setas envenenadas. Mas quem são elas realmente? As mitológicas sereias das viagens de Homero? As amazonas guerreiras da mitologia? Percebemos uma tentativa imagética da inversão da história da violência da conquista? Porque as amazonas parecem mais prestas em usar violência do que os portugueses.

No caso do segundo selo alemão (Figura 24a), a identificação é mais nítida: é o cacique Athore, filho do rei Sturiwa, da tribo dos Stuiriwa. Enquanto a pintura original (Figura 24b) sugere uma submissão do seu povo ao francês, este elemento é encoberto no segundo selo. Restam dois homens, aparentemente em conversa; ao fundo e no chão, os frutos da terra. Antigamente agrupados ao redor da coluna marco zero da conquista francesa, agora apresentados a René Goulaine de Laudonnière.

\subsection{Dois exemplos para a memória filatélica dos países sem colônias em Abya-Yala}

Seguem agora países que, no início da modernidade, não mantinham colônias nas Américas. Começamos com um país escandinavo, seguido por dois países do antigo Leste Europeu.

\section{Dinamarca}

A Dinamarca não menciona ouro nem prata, como Colombo na sua carta sobre a descoberta, mas lembra a importância crucial das Amé- 
A Alteridade Negada: 0 "Descobrimento" das Américas Segundo o Discurso Imagético...

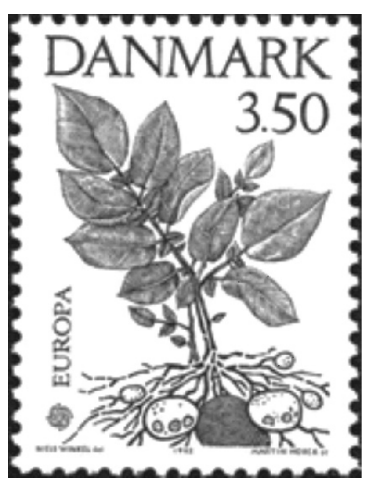

Figura 25

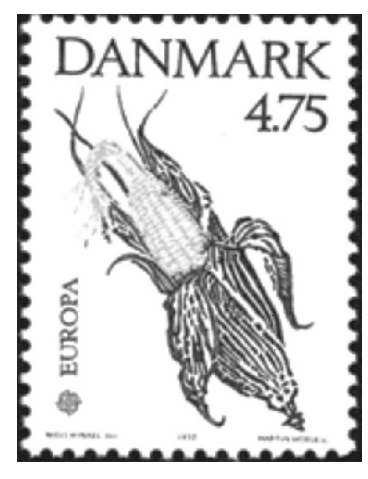

Figura 26

ricas para a sobrevivência da Europa e reproduz imagens da batata (Figura 25) e do milho (Figura 26). ${ }^{10}$

As imagens de plantas cultivadas remetem, indiretamente, à cultura dos seus cultivadores e de seus [suas] plantadores[as].

Os selos da Dinamarca quebram radicalmente o formato até então majoritariamente encontrado: não evidenciam a ação do conquistador.

\section{Hungria}

Depois de tanto encobrimento ou autoapresentação, a Hungria apresentou selos por meio dos quais se enxerga o outro (Figura 27; Figura

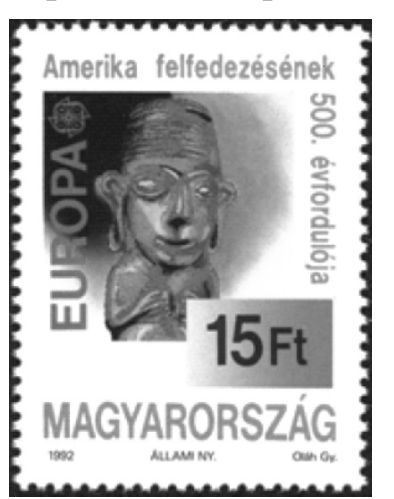

Figura 27

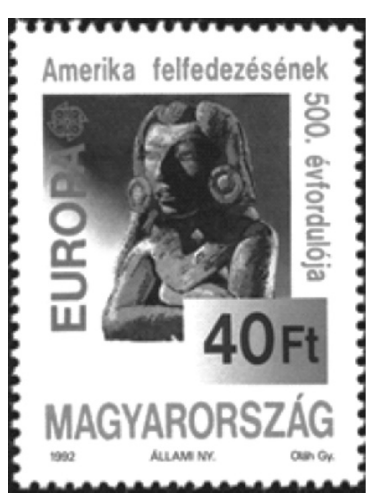

Figura 28 
28). Abya-Yala existia e pode ser representada. Abya-Yala tem história para contar. Refere-se a "500 évfordulója", ou seja, aniversário. Já felfedezésenek pode significar tanto descoberta como exploração. As figuras retratadas são da época "pré-colombiana", uma à base de ouro, a outra de terracota. Trata-se de culturas que dominam tecnologias da mineração, purificação e do tratamento de metais (Figura 28) e da reprodução artística de pessoas com traços pessoais. A esperança de encontrar metais preciosos aparece também na carta de Colombo de 1492. O ouro representa, então, uma das motivações centrais da descoberta. Dessa forma, articula o selo 27 não somente o nível cultural do outro, mas também o desinteresse europeu nessa sua cultura, que se interessa meramente pelo seu produto - o ouro e a pratae pela sua mão de obra para explorá-lo. Consequentemente, a grande parte dos artefatos dourados foram derretidos e transformados em barras de ouro antes de serem enviados para a Europa.

\section{Tchecoslováquia}

O selo da Tchecoslováquia introduz outra aproximação autônoma. A América é representada pelo busto de uma mulher (Figura 29); a Europa, por um busto masculino. Na água, um peixe ou uma serpente, aparentemente fugindo. Entre as figuras, uma troca de olhares. O homem vestido, a mulher nua. Os navios sem mulheres, as terras encontradas, sem homens. Com isso, o selo articula, no mínimo, indireta-

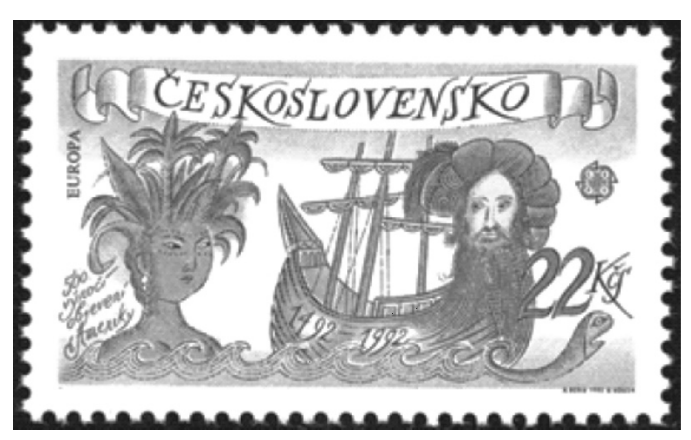

Figura 29 
A Alteridade Negada: 0 "Descobrimento" das Américas Segundo o Discurso Imagético...

mente, a práxis erótica como parte da "práxis guerreira, de violência pura [...] uma práxis erótica, pedagógica, cultural, política, econômica [...] do domínio dos corpos [...] da cultura [...] das instituições" (DUSSEL, 1993, p. 50). Dessa forma, é o único selo que serve para articular o drama das mulheres nativas e das mulheres escravas trazidas para as Américas durante a conquista e a época colonial.

\section{Negação da Alteridade, Encobrimento da História e a Transcrição dos Mitos da Modernidade}

Em conjunto, os selos das nações envolvidas na conquista das Américas representam, primeiro, nenhum reconhecimento das atrocidades cometidas, entre eles o genocídio entre as populações indígenas na América do Norte, na América Central e na América do Sul.

Alguns selos articulam de fato os interesses políticos, econômicos e religiosos atrás da conquista: Andorra, por exemplo, refere-se à carta de Colombo na sua edição de Basileia, mas coloca no seu selo uma imagem do rei espanhol que pertence à parte do texto que fala da reconquista da Espanha e da redenção de Granada. Os selos franceses apresentam justamente aquela região das Américas que até hoje pertencem à França, não as regiões "perdidas", com partes de Canadá e da América do Norte. Um selo húngaro menciona o ouro e com ele, indiretamente, a cobiça europeia pelo metal nobre e a instalação de um sistema de mineração com condições sub-humanas para os mineiros. Indiretamente, transparece o tema também quando se menciona a carta de Colombo nos selos alemães, por se referir ao ouro, algo que Sir Walter Raleigh (mencionado em um selo da Ilha de Jersey) como pirata da Rainha Elizabeth tentou roubar dos espanhóis. O tema da "corrida" dos selos ingleses e a indicação da direção da viagem para o oeste no selo holandês deixam transparecer a competição entre as nações europeias em busca do acesso às riquezas da Índia. Os 


\section{Helmut Renders}

selos espanhóis focam em conjunto com os selos da Andorra espanhola na participação da igreja na conquista, desde o processo de convencer o casal dos monarcas de assistir o projeto até a sua participação na implantação do sistema colonial. $\mathrm{O}$ aspecto religioso transparece também nos selos da Ilha de Man e da Ilha de Jersey, referindo-se aos pais peregrinos e outros grupos de fugitivos religiosos que procuram um recomeço na América do Norte. E o selo da Tchecoslováquia, mesmo de forma sutil, refere-se aos encontros entre conquistadores, mulheres nativas e escravas que seguem a descoberta que faz parte dos imensos crimes cometidos nesse processo.

Essas articulações, porém, são sutis, e visíveis na sua maior parte somente para quem entra em uma conversa mais profunda com essas representações da cultura visual. Além dessa visibilidade indireta, existem omissões que transformaram esses relatos das descobertas de fato em encobrimentos. Os selos alemães, além de não tocar no intermezzo alemão na Venezuela, transformam dois relatos imagéticos altamente políticos que visualizaram claramente os interesses de monarquias europeias na conquista em relatos de descobertas e encontros, entre seres humanos e culturas. Os selos portugueses não falam do suporte religioso dos jesuítas, tão importante no seu projeto de conquista. Os franceses não dizem nada sobre a sua presença na América do Norte e na América do Sul, envolvendo protestantes (huguenotes na Flórida e na França Antártica/Rio de Janeiro) e católicos (jesuítas, na Califórnia, no Canadá e até em Nova Orleans). A "práxis guerreira, de violência pura [...] uma práxis erótica, pedagógica, cultural, política, econômica [...] do domínio dos corpos [...] da cultura [...] das instituições" (DUSSEL, 1993, p. 50), na sua grande maioria, não é assunto dos selos.

Esses selos, parte da cultura visual dos seus países e do seu continente, quando se referem à descoberta das Américas, compartilham um posicionamento político. Apesar de cada país ter seus processos específicos para escolher artistas e suas propostas, com outras pala- 


\section{A Alteridade Negada: 0 "Descobrimento" das}

Américas Segundo o Discurso Imagético...

vras, há um tema em comum, mas não uma orquestração detalhada da criação e produção desses selos, os discursos distintos se aproximam. Prorrogam-se e propagam-se interpretações que revelam a visão europeia, e encobrem a realidade estabelecida nas Américas. $\mathrm{O}$ que aconteceu em público, como parte do cotidiano do mundo da comunicação, mostra não somente a sobrevivência de discursos antigos, mas sua vitalidade e sua presença na construção de significados e reafirmação desses discursos.

Certos aspectos dos diversos discursos visuais podem ser identificados com as distinções de Todorov e Dussel. Por exemplo, podemos interpretar a ausência de julgamentos de valor nos selos como expressão do espírito modernista. Não se julga o outro, mas também não existe uma autoavaliação crítica. Prorrogam-se antigos discursos de bravura e heroísmo, da singularidade do ser humano europeu, da sua inteligência tecnológica. Não se introduz categorias éticas, não se lembram de acontecimentos-chave como o genocídio e o sofrimento, a relação entre colonizadores e colonizados. Em termos gerais, parece-nos que o eixo interpretativo mais marcante é aqui a ação, o espírito de empreendimento. As ações são ousadas: o enfrentamento do desconhecido, a imensidão do mar, o avançar sem saber e ter certezas. Mas, não se fala do desejo da submissão, no mínimo, da assimilação. Procura-se conhecer para submeter, não para respeitar.

Enquanto Europa, descobre uma nova situação geopolítica; Abya-Yala descobre os europeus como invasores e o consequente encobrimento e negação das suas conquistas culturais como povos das Américas e o roubo das suas riquezas. O olhar da perspectiva de Abya-Yala quase não é mencionado. Como vimos, o abandono do discurso de Colombo ainda não significa um discurso não eurocêntrico. Muitas vezes, os países trocam o discurso em memória de Cristóvão Colombo por um discurso que destaca representantes do seu país, ou como exploradores corajosos, ou como conquistadores bem-sucedidos. 
Graças à acessibilidade dos estudos diferenciados e autocríticos, estamos hoje, mais do que sempre, na condição de ver como se tratava a alteridade entre as antigas nações coloniais e suas anteriores colônias. Percebemos que, em um nível bastante comum e bem situado no cotidiano, a partir de selos colocados em circulação pelos governos da União Europeia, o desencontro, o encobrimento ou a mera negação da existência do outro e das suas condições da vida representam até hoje uma estratégia de contar a história da relação da Europa com as Américas como um caso feliz de descoberta. Sem uma memória de outras histórias dessa relação, continuará se fortalecendo a sedimentação do não encontro e do encobrimento.

\section{Notas}

1. Esta edição anual se iniciou com os países da União Montana em 1956. Participaram, até 1959, Alemanha, Bélgica, França, Itália, Luxemburgo e Países Baixos. O número cresce para 19 em 1959, 26 em 1969 e 44 em 1992.

2. Trata-se de Andorra, Bulgária, Chipre (parte grega e parte turca), Finlândia, Grécia, Gibraltar, Ilha de Guernsey, Ilha de Jersey, Malta, Mônaco, Polônia, Portugal, Romênia, Suíça e Iugoslávia.

3. Euro CEPT envolveu tanto países da União Europeia (em 1992, eram: Bélgica, Alemanha, França, Itália, Luxemburgo, Holanda, Grã-Bretanha, Irlanda, Dinamarca, Grécia, Portugal e Espanha) como outros países europeus: Açores, Andorra (francês), Andorra (espanhol) Áustria, Bulgária, Chipre (parte grega e parte turca), Croácia, Finlândia, Gibraltar, Ilhas Faro, Ilha de Guernsey, Ilha de Jersey, Ilha de Man, Iugoslávia, Islândia, Liechtenstein, Malta, Madeira, Mônaco, Noruega, Polônia, Romênia, San Marino, Suécia, Suíça e Turquia.

4. Carlo V cedeu à família Welser, banqueiros de Augsburgo, Alemanha, o direito de colonizar a Venezuela. Com a chegada do governador Ehinger, iniciou-se a presença alemã em 1529, que se estendeu até 1546.

5. Bloco 1: Cristobal Colón; bloco 2: Los viajes de Colón - Solicitando el apoyo real; bloco 3: Los viajes de Colón - Avistando tierra; bloco 4: Los viajes de Colón - Tomando posesión del Nuevo Mundo; bloco 5: Los viajes de Colón 


\section{A Alteridade Negada: 0 "Descobrimento" das}

Américas Segundo o Discurso Imagético...

- Relatando el descubrimiento; bloco 6: Los viajes de Colón - Restitución del favor real.

6. Interessantemente, aparece uma gravura da segunda parte da carta de Colombo em um dos selos alemães (Figura 25).

7. Os Açores foram também o primeiro lugar onde os portugueses implantaram seu sistema escravagista na produção de açúcar à base de cana.

8. As escolas temáticas que estes selos representam podem ser comparadas também com outra iniciativa filatélica do ano 1992. A Espanha fez também parte da União Postal da América e Espanha (UPAE), a qual, em 1989, foi ampliada por Portugal para a União Postal da América, Espanha e Portugal (UPAEP). Isso nos dá uma oportunidade de comparar o discurso interno europeu com o discurso em conjunto dos países da UPAEP. O grupo definiu como temas de selos comemorativos para os anos de 1989 até 1992 as seguintes ênfases: 1989: Povos pré-colombianos - hábitos e costumes; 1990: O meio ambiente encontrado pelos descobridores; 1991: As viagens de descoberta; 1992: O quincentenário da descoberta de América. A comparação entre os selos produzidos pela UPAEP e pela UE mostra a possibilidade de um discurso alternativo em relação a 1492 .

9. O monumento sobreviveu aos tempos e existe até hoje perto de Jacksonville.

10. A importância do milho para a Coroa portuguesa fica evidente quando se percebe que ele se tornou elemento decorativo dos azulejos em diversas salas do Palácio Nacional em Sintra.

\section{Referências Bibliográficas}

ALtMAN, D. Paper Ambassadors, the Politics of Stamps. North Ryde: Angus \&? Robertson, 1991.

ATHREYE, S.; BROWN, W.; BROMLEY, S. (Org.). Ordering the International: History, Change and Transformation. Londres: The Open University, 2004. 
CHILD, J. Miniature Messages, the Semiotics and Politics of Latin American Postage Stamps. Durham: Duke University Press, 2008.

CUSACK, I. Tiny Transmitters of National and Colonial Ideology: The Postage Stamps of Portugal and its Empire. Nations and Nationalism, v. 11, n. 4, p. 591-612, 2005.

DEANS, P.; DOBSON, D. Introduction, East Asian Postage Stamps as Socio-Political ArtiFacts. East Asia, v. 22, n. 2, p. 3-7, 2005.

DUSSEL, E. O encobrimento do outro: a origem do mito da modernidade. Conferências de Frankfurt. Tradução de Jaime A. Clasen. Petrópolis: Vozes, 1993.

FREWER, D. Japanese Postage Stamps as Social Agents: Some Anthropological Perspectives. Japan Forum, v. 14, n. 1, p. 1-19, 2002.

MENESES, U. T. Bezerra de. Fontes visuais, cultura visual, história visual, balanço provisório, propostas cautelares. Revista Brasileira de História, São Paulo, v. 23, n. 45, p. 11-36, 2003.

MITCHELL, W. J. T. Iconology, image, text, ideology. Chicago: The University of Chicago Press, 1987.

. Picture Theory, Essays on Verbal and Visual Representation. Chicago: The University of Chicago Press, 1994.

NEWMAN, R. S. Orientalism for Kids: Postage Stamps and "Creating” South Asi. Journal of Developing Societies, v. 5, n. 1, p. 70-82, 1989.

RAENTO, P.; BRUNN, S. Visualizing Finland: Postage Stamps as Political Messengers. Geografiska Annaler, v. 87b, n. 2, p. 145-163, 2005.

REID, D. M. The Symbolism of Postal Stamps: A Source for the Historian. Journal of Contemporary History, v. 19, n. 2, p. 223-249, 1984.

RENDERS, H. O fundamentalismo na perspectiva da teoria da imagem, distinções entre aproximações iconoclastas, iconófilas e iconólatras às representações do divino. Estudos de Religião, ano 22, n. 35, p. 87-107, 2008.

Deus, o ser humano e o mundo nas linguagens imagéticas da religião do coração, códigos e projetos. Pistis \& Praxis, v. 1, n. 2, p. 373-413, 2009a. 


\section{A Alteridade Negada: 0 "Descobrimento" das}

Américas Segundo o Discurso Imagético...

Imaginário religioso católico - protestante - pentecostal - neopentecostal? Implicações da origem e múltiplas reedições do Livrinho do Coração e em solo brasileiro. Ciências da Religião - História e Sociedade, v. 7, n. 2, p. 116-153, 2009b.

SALCEDO, D. A. Lacunas na arquivologia contemporânea, uma perspectiva da filatelia. Arquivistica.net, Rio de Janeiro, v. 2, n. 1, p. 104-113, 2006.

Filatelia e memória, pequenos embaixadores de papel. In: VERRI, G. M. W. (Org.). Registros do passado no presente. Recife: Bagaço, 2008.

TODOROV, T. A conquista da América, a questão do outro. Tradução de Beatriz Perrone Moisés. 3. ed. São Paulo: Livraria Martins Fontes Editora Ltda, 1991.

WULF, C. Homo pictor: imaginação, ritual e aprendizado mimético no mundo globalização. São Paulo: Hedra, 2013.

\section{Resumo}

\section{A Alteridade Negada: 0 "Descobrimento" das Américas Segundo o Discurso Imagético de Selos Europeus de 1992}

A ideia do outro diferente é nas relações internacionais um aspecto importante para a forma do estabelecimento e da manutenção dessas relações. Enquanto os discursos e as declarações de políticos e governos passam hoje por filtros profissionais jurídicos e políticos sofisticados, existem outras expressões culturais que estabelecem discursos oficiais paralelos. Este artigo apresenta as representações do outro nos selos postais europeus lançados por ocasião das celebrações da chamada descoberta da América em 1992. Como referencial teórico, parte das reflexões sobre alteridade ou outridade de Tzvetan Todorov (1991) e Enrique Dussel (1993). Como método, propõe uma análise das narrativas imagéticas dos selos como expressões de suas respectivas culturas visuais. O estudo identifica o discurso imagético dominante e apresenta três discursos alternativos.

Palavras-chave: América Latina e Europa - 500 Anos do Descobrimento da América - Selos Euro CEPT 1992 - Alteridade - Outridade - Tzvetan Todorov - Enrique Dussel 
Abstract

\section{Otherness Denied: The \\ "Discovery" of the Americas in the Pictorial Discourse of European Stamps from 1992}

The idea of the different as other is in international relations an important aspect for the establishment and maintenance of these relations. While the pronouncements and statements of politicians and governments pass through political filters provided by legal professionals there are other cultural expressions that establish official but parallel discourses. As an example this paper presents the representations of the other in European postage stamps launched on the occasion of the celebrations of the so-called discovery of America. As theoretical reference, the investigation dialogues with the reflections on alterity or otherness provided by Tzvetan Todorov (1991) and Enrique Dussel (1993). As method we propose an analysis of the imagetic narratives of the stamps as expression of visual culture. The study identifies the dominant imagetic discourse and presents three alternative ones.

Keywords: Latin America and Europe - 500 Years of Discovery of America - EURO CEPT Stamps from 1992 - Alterity - Otherness - Tzvetan Todorov - Enrique Dussel 